2.71; above TLV 1.95, 95\% CI: 1.27 to 3.00). About one third of CTS cases were attributable to exposure levels above the AL.

Conclusions The ACGIH TLV method predicted the risk of CTS, but the dose-response was flat above the AL: a fine-tuning of the proposed thresholds should be considered.

\section{1b RISK FACTORS FOR CARPAL TUNNEL SYNDROME - FINDINGS FROM THE NIOSH UPPER EXTREMITY MUSCULOSKELETAL DISORDER CONSORTIUM}

BA Evanoff* , E Eisen, F Gerr, S Burt, K Hegmann, B Silverstein, A Garg, AM Dale, S Bao, C Harris-Adamson, J Kapellusch, L Merlino, D Rempel. Division of General Medical Science, Washington University School of Medicine, Saint Louis, MO, USA

\subsection{6/oemed-2018-ICOHabstracts.738}

Starting in 2000, six research groups from the USA were supported by NIOSH to perform large, prospective epidemiologic studies examining associations between workplace physical risk factors and upper limb musculoskeletal disorders. A total of 4321 workers at 55 employers/plants across a variety of handintensive industries were followed for up to six years. Individual workplace exposure data included direct observation and video analysis. Health data included self-report, physical examination, and nerve conduction measures; our case definition for carpal tunnel syndrome (CTS) required both typical symptoms and nerve conduction abnormalities. Those performing the physical examinations and the video analyses were blinded to exposure and medical condition, respectively. Pooled analyses of consortium data controlled for personal factors (age, body mass index, gender, co-morbid diseases) and non-overlapping physical exposures (force, posture repetition) to study the association between work exposures and carpal tunnel syndrome. We found no independent effects of wrist posture or total repetition rate on the incidence of CTS. In contrast, strong dose-dependent associations were found between incident CTS and peak hand force (Borg CR10 $\geq 3$ ), forceful repetition rate $(>3$ exertions per minute of $\geq 9 \mathrm{~N}$ pinch force or $45 \mathrm{~N}$ power grip), and the proportion of time spent in forceful exertion $(>11 \%)$. We also found that the ACGIH Threshold Limit Value for Hand Activity (TLV for HAL) predicted CTS, and that that current 'action limit' is too high to adequately protect workers. Varying the formula of the TLV to emphasise force over repetition better predicted incident CTS. Study findings suggest that efforts to reduce workplace exposures should focus on jobs requiring high hand force and repeated or prolonged forceful exertions. Our study also suggests that the TLV for HAL and other less labour intensive assessment methods are valid and usable tools for workplace prevention.

\section{C RECENT CHANGES TO THE ACGIH HAND ACTIVITY LEVEL TLV}

D Rempel*. Division of Occupational and Environmental Medicine, University of California, San Francisco, USA

\subsection{6/oemed-2018-ICOHabstracts.739}

The ACGIH Hand Activity Level (HAL) Threshold Limit Value (TLV) is a risk assessment tool designed to protect workers, who perform repetitive hand exertions for 4 or more hours per day, from distal upper extremity disorders. Recent large, longitudinal studies, provide strong evidence that repetitive forceful hand exertions increase risk for occupational wrist tendinosis and carpal tunnel syndrome. ${ }^{1,2,3}$ In the Harris-Adamson study, ${ }^{3}$ forceful hand exertions (e.g., $>9 \mathrm{~N}$ pinch or $>45 \mathrm{~N}$ power grip force) and the $\%$ time performing forceful hand work increased risk. Based on these and psychophysics studies, ${ }^{4}$ hand exertions should be considered in risk assessment models if they are above $10 \%$ of posture specific strength. In addition, in these large studies, the prior HAL TLV action limit (0.56) was not sufficiently protective ${ }^{5}$ and, therefore, has been revised. The name of this TLV was changed to Hand Activity (HA) TLV. Other changes to the TLV will also be presented.

\section{REFERENCES}

1. Harris C, Eisen E, Goldberg R, et al. Workplace and individual factors in wrist tendinosis among blue-collar workers: The San Francisco study. Scand J Work Environ Health 2011;37(2):86-98.

2. Bonfiglioli $R$, Mattioli $S$, Armstrong $T$, et al. Validation of the ACGIH TLV for hand activity in the OCTOPUS cohort: A two-year longitudinal study of carpal tunnel syndrome. Scand J Work Environ Health 2013;39:155-63.

3. Harris-Adamson C, Eisen EA, Kapellusch J, et al. Biomechanical risk factors for carpal tunnel syndrome: A pooled study of 2474 workers. Occup \& Environ Medicine 2015;72:33-41.

4. Potvin JR. Predicting maximum acceptable efforts for repetitive tasks an equation based on duty cycle. Human Factors 2012;54(2):175-188.

5. Kapellusch JM, Gerr F, Malloy EJ, et al. Exposure-response relationships for the ACGIH TLV for hand activity level: Results from a pooled data study of carpal tunnel syndrome. Scand J Work Environ Health 2014;40:610-20.

\section{1d QUANTIFYING COMPLEX TASKS USING THE REVISED STRAIN INDEX}

JM Kapellusch*, A Garg. University of Wisconsin - Milwaukee, Milwaukee, USA

\subsection{6/oemed-2018-ICOHabstracts.740}

Modern occupational tasks are often complex - consisting of multiple, discrete sub-tasks, each with its own unique combination of force, duration of exertion, posture, and frequency. Quantifying the physical stress from these complex tasks using simple, 'mono-task' assessment tools, such as the 1995 Strain Index (SI), can be difficult and assumes a large degree of ergonomics and MSD knowledge and training. Compared to the 1995 SI, the Revised Strain Index (RSI) minimises complicated measurement decisions and improves upon the 1995 SI by: (1) using percent maximum voluntary contraction (or Borg CR-10 equivalent) for applied hand force, (2) using duration per exertion (in seconds) rather than duty cycle, and (3) distinguishing between flexed and extended wrist postures. Thus the stress from each effort of a task (i.e., each sub task) can be individually quantified by the RSI and compared to other efforts in a cycle, or alternative efforts in the case of task intervention. By incorporating frequency of exertions (i.e., efforts per minute) and duration of task (i.e., hours per day), the RSI summarises stress associated with a simple task in a manner similar to the 1995 SI. For complex tasks, the RSI incorporates the Composite Strain Index (COSI) algorithm which integrates individual sub-tasks into an aggregate COSI score. The algorithm rank-orders subtasks from most to least stressful, thus ensuring that total task-stress is not lower than that of the highest stress sub-task alone. Sub-tasks are then incrementally added to one another by integrating over the frequency of exertion multiplier to produce the final COSI 
score (with all exertions explicitly represented). This presentation describes the RSI and COSI algorithm. A brief complex task example compares the RSI to the 1995 SI and showcases the RSI's much improved utility as a tool for the design and evaluation of complex tasks.

\section{1e UPDATE ON GERMAN RISK ASSESSMENT TOOLS FOR UPPER LIMB MSDS}

B Weber*, U Hoehne-Hückstädt, D Ditchen, D Seidel, I Hermanns, R Ellegast. Institute for Occupational Safety and Health of the German Social Accident Insurance (IFA), Sankt Augustin, Germany

\subsection{6/oemed-2018-ICOHabstracts.741}

In Germany, several tools for the risk assessment of physical workload are available for different applications. Besides different screening methods, there are technical systems that can be used in the field and/or laboratory. The focus of the work of the Institute for Occupational Safety and Health of the German Social Accident Insurance (IFA) is located on the risk assessment of physical workload using technical measurements $\left(\mathrm{CUELA}^{1}\right)$. By providing assessment procedures for different body regions, an important gap in the prevention of workrelated MSDs is to be closed here. Regarding risk assessment for upper limb MSDs, the IFA develops procedures for evaluating workload on the wrist, elbow and shoulder. To newly develop an assessment procedure for the elbow load a systematic review was carried out, for instance. The activities for assessing the shoulder load are also part of the PEROSH joint research project 'PEROSH recommendations for procedures to measure occupational physical activity and workload' having one focus on the assessment of upper arm elevation at work with technical systems. ${ }^{2}$ Within the framework of a joint project of the Federal Institute for Occupational Safety and Health (BAuA) and the German Social Accident Insurance (DGUV) (MEGAPHYS - multilevel risk assessment of physical workload) it is intended to use the IFA assessment procedures for about 120 workplaces where the physical workload was measured by CUELA. The workload data is for example to be correlated with subjectively perceived strain and complaint data from questionnaires, interviews and physical examinations collected from about 1000 employees.

\section{REFERENCES}

1. Ellegast R, Hermanns I, Schiefer C. Workload assessment in field using the ambulatory CUELA system. In (Duffy VG ed.). Second International Conference on Digital Human Modelling - ICDHM 2009: Held as Part of HCl International 2009 July 19-24. San Diego. Berlin: Springer:221-6.

2. http://www.perosh.eu/research-projects/perosh-projects/perosh-recommendationsfor-procedures-to-measure-occupational-physical-activity-and-workload/

\section{MUSCULOSKELETAL COMPLAINTS AMONG OFFICE WORKERS: COMPLEMENTARY ROLE OF PHYSICAL, PSYCHOSOCIAL AND ENVIRONMENTAL JOB DEMANDS AND RESOURCES}

1,2 Liesbeth Daenen*, ${ }^{1,3}$ Tinne Vander Elst, ${ }^{1}$ Veerle Hermans, ${ }^{1}$ Chris Verbeek, ${ }^{1}$ David Verwimp, ${ }^{1,4}$ Lode Godderis. ${ }^{1}$ Knowledge, Information and Research Centre, Group IDEWE (External Service for Prevention and Protection at Work), Louvain, Belgium; ${ }^{2}$ Department of Rehabilitation Sciences and Physiotherapy, Human Physiology and Anatomy (KIMA), Faculty of Physical Education and Physiotherapy, Vrije Universiteit Brussel, Brussels, Belgium; ${ }^{3}$ Research Group Work, Organisational and Personnel Psychology, Faculty of Psychology and Educational Science, KU Leuven, Louvain, Belgium; ${ }^{4}$ Environment and Health, Faculty of Medicine, KU Leuven, Louvain, Belgium

\subsection{6/oemed-2018-ICOHabstracts.742}

Introduction Work-related musculoskeletal disorders (WMRDs) are the most important causes of work disability and longterm absenteeism among office workers. A wide range of risk factors of physical, psychosocial and environmental nature has been identified, but the question remains as to which degree these factors contribute to WMRDs and which explanatory mechanism underlies this relationship. Therefore, an integrated model corresponding to the scientific literature and the Job Demands-Resources model was used to examine (1) the effects of both job demands (e.g. workload, prolonged sitting, glare/ reflection) and job resources (e.g. social support, accurate workplace settings) on WMRDs and (2) the mediating role of emotional exhaustion and cognitive stress complaints in the relationship between these job demands/resources and WMRDs in office workers.

Methods Thousand office workers from several Belgian companies participated in the study. They were asked to fill out a structured online questionnaire including socio-demographic characteristics, work-specific factors and job demands/resources covering four work-related domains (i.e. work experience, workstation, work environment and movement). Path analysis by means of Mplus 7.4 was conducted to test the hypotheses. Results Most commonly reported complaints were located in the back (48\%) and neck (34\%). Multiple direct effects were found between measured job demands/resources and WMRDs, but only lower levels of social support predicted self-reported pain at all body regions $(\mathrm{p}<0.05)$. Regarding the indirect effects, emotional exhaustion was the most important mediator as it mediated the relationships between workload, noise, social support, autonomy, and WMRDs $\left(\mathrm{k}^{2}\right.$ values from 0.02 to 0.07$)$.

Discussion The results indicate that (1) physical, environmental as well as psychosocial job demands/resources are related to WRMDs and (2) emotional exhaustion is an important explanation. These association and mediation patterns suggest opportunities for intervention strategies in order to stimulate accurate workplace settings, improve work experience (with special attention to social support) and prevent emotional exhaustion. 